\title{
Formation of Antireflection Thin-Film Glasses Using Organopolysiloxane by Low-Temperature Process and Surface Modification
}

\author{
Hiroyuki Miwa ${ }^{1, *}$, Atsuki Kodama ${ }^{1}$, Htay Win $^{1}$, Koichi Murakami $^{1}$, Taku Takahashi ${ }^{2}$, \\ Fumitaka Ohashi ${ }^{2,3}$ and Shuichi Nonomura ${ }^{1,3}$ \\ ${ }^{1}$ Environmental and Renewable Energy Systems Division, Graduate School of Engineering, Gifu University, Gifu 501-1193, Japan \\ ${ }^{2}$ Department of Electrical and Electronics, Faculty of Engineering, Gifu University, Gifu 501-1193, Japan \\ ${ }^{3}$ Next Generation Energy Research Center, Gifu University, Gifu 501-1193, Japan
}

Porous $\mathrm{SiO}_{\mathrm{x}}$ thin films were prepared using a commercial liquid glass (LG) based on organopolysiloxane to improve the conversion efficiency of photovoltaic modules as antireflection films. Optimization of the preparation of porous $\mathrm{SiO}_{\mathrm{x}}$ films such as the ink manufacturing process was carried out by adding isopropyl alcohol (IPA) to the LG, spin coating, and annealing. Adding an ultrapure water (UW) to the ink with subsequent annealing at $300^{\circ} \mathrm{C}$ resulted in the formation of a porous $\mathrm{SiO}_{\mathrm{x}}$ thin film with $4.6 \%$ reflectance at $600 \mathrm{~nm}$ wavelength, whose refractive index was estimated to be 1.33 , which is lower than that of conventional antireflection coating films such as $\mathrm{MgF}_{2}$. In addition, the antireflection effect of the antireflection film fabricated at room temperature without dilution with UW was improved by surface modification by performing excimer vacuum ultraviolet (VUV) irradiation at room temperature and atmospheric pressure. This treatment modified the reflectance of the film from $8.1 \%$ to $7.7 \%$ at $600 \mathrm{~nm}$ and the refractive index from 1.44 to 1.42 , which is lower than that of normal glass. [doi:10.2320/matertrans.M2017332]

(Received November 2, 2017; Accepted November 21, 2017; Published December 22, 2017)

Keywords: antireflection film, liquid glass, surface modification, solar cell, excimer irradiation

\section{Introduction}

The formation of antireflection films (ARFs) on the cover glasses of photovoltaic (PV) modules is an effective method of maximizing the performance of PV modules. ${ }^{1-3)}$ The ARF coating reduces the reflection at the surface of the cover glass and increases the intensity of incident light reaching the PV device by optical matching, controlled by the refractive index and thickness of the ARF. ${ }^{4)}$ However, most existing solar cells do not have an ARF at the interface between the atmosphere and the cover glass, and thus the potential of solar cells is not fully achieved. It was reported in Global Status Report 2017 of Renewable Energy Policy Network for the $21^{\text {st }}$ Century that the capacity of worldwide PV power generation exceeded $300 \mathrm{GW}$ at the end of 2016. However, the rate of increase in this capacity is considered to be insufficient to achieve the Paris Agreement. In places where it is difficult to install more solar cells, such as individual houses or roofs of buildings, the output of existing facilities can be increased by replacing the solar cells with higher-output ones. Increasing the output of existing facilities is an important issue in terms of reducing environmental impact at a low cost as well as increasing efficiency of solar cells produced in the future. From this standpoint, it is desirable to develop low-cost technologies for producing ARFs for use on the glasses covering existing PV modules together with those for producing new PV modules.

Magnesium fluoride $\left(\mathrm{MgF}_{2}\right)$ is commonly used as an ARF in conventional optical devices because its refractive index $(\mathrm{n} \cong 1.38)$ is between that of $\operatorname{air}(\mathrm{n}=1)$ and glass $(\mathrm{n} \cong 1.5)$ and because of its high adhesiveness on the smooth surface of a glass substrate. ${ }^{5,6)}$ However, the ideal refractive index of ARFs is in the range of 1.21 to 1.25 for their use on the cover glass in actual PV modules. ${ }^{7,8)}$ In addition, the solubil-

*Corresponding author, E-mail: w3915101@edu.gifu-u.ac.jp ity of $\mathrm{MgF}_{2}$ results in poor durability when used with the PV modules, which are typically used outdoors for more than 20 years. Furthermore, a vacuum process is needed for the conventional preparation of $\mathrm{MgF}_{2}$ films, which results in high production costs and difficulties in large-scale applications. Thus, the development of a new material for ARFs is necessary.

The porous $\mathrm{SiO}_{\mathrm{x}}$ is a potential material for achieving an ARF coating with lower reflection and is insoluble in water. Porous $\mathrm{SiO}_{\mathrm{x}}$ films have already been fabricated by the solgel method, which reduced the refractive index to 1.3 . However, a high annealing temperature in the range of 500 to $900^{\circ} \mathrm{C}$ and complicated fabrication processes are required, which would increase the manufacturing cost of PV modules. ${ }^{9,10)}$

To overcome the above disadvantages, we have focused on liquid glass (LG) as a material for ARFs. LG is a liquid material at room temperature that becomes solid $\mathrm{SiO}_{\mathrm{x}}$ upon curing, which has similar properties to solid glass. It is generally used as a coating material to avoid mechanical damage to car paints and as an architectural materials because of its hardness. ${ }^{11,12)}$ In addition, the liquid phase in the starting material makes it possible to easily modify the proportion of subsequent materials by adding substances to the LG and changing the curing conditions and to apply LG to largescale devices.

In this paper, we report the preparation of porous $\mathrm{SiO}_{\mathrm{x}}$ on glass substrates with a low refractive index by using an organopolysiloxane-based LG. Both the size and number of voids are controlled by the doping materials and annealing at $300^{\circ} \mathrm{C}$ to produce porous $\mathrm{SiO}_{\mathrm{x}}$ for use on new PV modules. Furthermore, results of the surface modification of porous $\mathrm{SiO}_{\mathrm{x}}$ thin film by excimer vacuum ultraviolet (VUV) light irradiation are presented, which can be applied to existing PV modules. Two important technologies for controlling the size of the voids and the modification of the surface on 
porous $\mathrm{SiO}_{\mathrm{x}}$ films are proposed that utilize the organopolysiloxane- based LG.

\section{Experimental Method}

An LG (type G, NARUSE SEIJOU Ltd.) based on organopolysiloxane was sued with a mixture of isopropyl alcohol (IPA, 99.5\%, Wako) and ultrapure water (UW) as the starting materials of the ARFs in this study. The dilution ratio of the materials was LG : IPA : UW $=1: \mathrm{X}: \mathrm{Y}$ in volume, where $X=3-9$ and $Y=0-0.5$. The mixed solution was stirred at a speed of $1400 \mathrm{rpm}$ for $10 \mathrm{~min}$. Then, the solution was pipetted onto a clean glass substrate (Eagle XG, Corning Glass) and spin-coated with a speed of 1000 to $8000 \mathrm{rpm}$. The thicknesses of the ARFs varied in the range of $150 \pm 50 \mathrm{~nm}$ depending on the coating speed. The solution-coated substrate was then annealed or dried at 100 $500^{\circ} \mathrm{C}$ in an electric furnace for $1 \mathrm{~h}$ or at room temperature for 7 days. Both annealing processes were performed under atmospheric pressure.

For the surface modification of the ARFs, the irradiation of excimer VUV using an excimer lamp (SUS05, USHIO Inc.) was performed. This excimer lamp irradiated $172 \mathrm{~nm}$ excimer light. The reflectance of the ARFs was measured using a UV-VIS spectrophotometer (V-670, JASCO Co.) and the distribution and sizes of internal pores were analyzed by the diffuse measurement of small-angle $\mathrm{x}$-ray scattering (Rigaku, Smart Lab, Nano Solver). The approximate thickness and refractive index of the prepared thin film were estimated by curve fitting of the reflectance spectra and interference fringes.

\section{Results and Discussion}

The reflectance spectra of ARFs formed with a fixed dilution ratio and spin-coating speed (LG : IPA : UW $=1: 5: 0$, $8000 \mathrm{rpm}$ ) but different annealing temperatures are shown in Fig. 1 As the annealing temperature is decreased, the reflectance spectrum decreases to a certain minimum value and then tends to increase from the minimum value. The dependence of the refractive index on the annealing temperature was also examined. The proportion of voids present in the film and its refractive index were estimated by fitting the

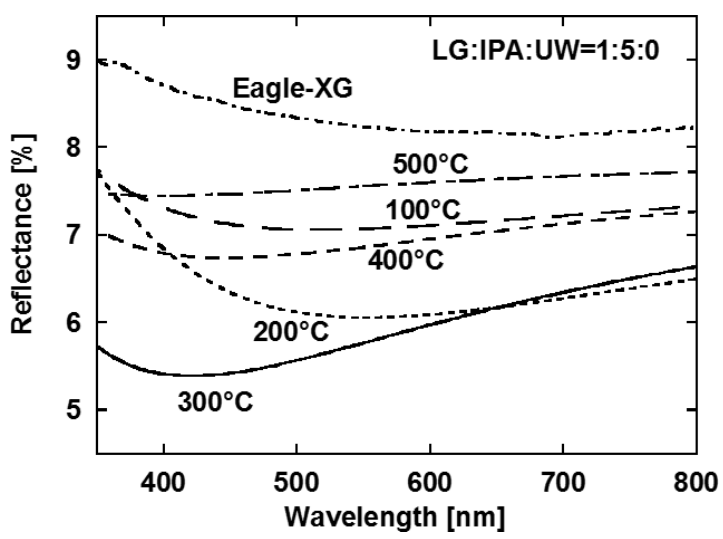

Fig. 1 Reflectance spectra of ARFs formed at different annealing temperatures. curve of the reflectance spectrum.

Figure 2 shows that the refractive index at $600 \mathrm{~nm}$ with respect to the annealing temperature of the electric furnace, and a proportion of voids. The refractive index and void ratios in Fig. 2 were estimated from the reflectance spectra of Fig. 1 The void ratio is maximum at $300^{\circ} \mathrm{C}$. It was found that the rotation speed of the spin coating did not significantly change the void ratio in the film, but did change the film thickness.

From the chemical reaction formula of organopolysiloxane, which is the main raw material of the LG, it was considered that adding UW to the mixed solution of LG and IPA could change the reaction rate and increase the void ratio in the film. The refractive index, ink volume ratios, spin-coating speeds, annealing temperatures, and annealing times of the ARFs in Fig. 3 are shown in Table 1. The minimum refractive index of 1.33 was obtained at an ink volume ratio (LG : IPA : UW) of $1: 4.85: 0.15$ as shown in Fig. 3 However, ARFs with lower reflectivity could be fabricated from the diluted LG ink. Adding the UW to the ink with subsequent annealing at $300^{\circ} \mathrm{C}$ resulted in the formation of a porous $\mathrm{SiO}_{\mathrm{x}}$ thin film with $4.6 \%$ reflectance at $600 \mathrm{~nm}$ wavelength whose refractive index was estimated to be 1.33 , which is lower than that of conventional antireflection coating film such as $\mathrm{MgF}_{2}$. A comparison of the reflectance spectra of Eagle XG glass, a $\mathrm{MgF}_{2}$ film, and ARFs made from the ink with and without dilution is shown in Fig. 4



Fig. 2 Refractive index (at $600 \mathrm{~nm}$ ) and the proportions of voids in ARFs formed with different annealing temperatures.

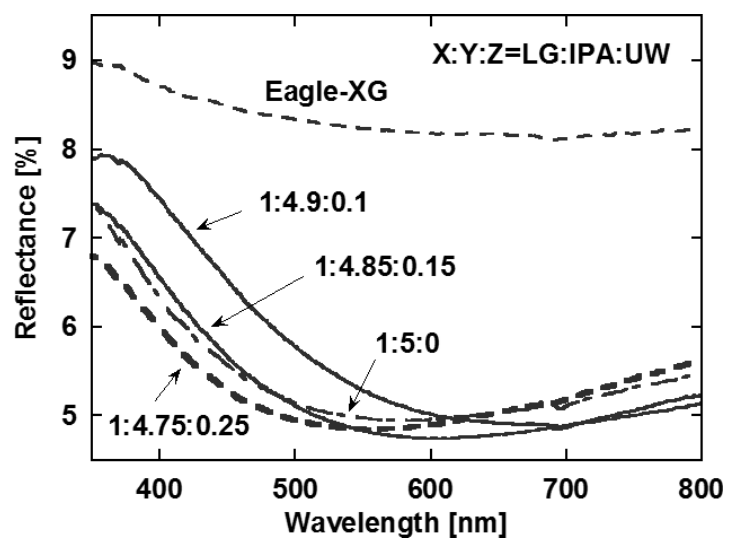

Fig. 3 Reflectance spectra of ARFs with different dilution ratios. 
Table 1 Reflective index (at $600 \mathrm{~nm}$ ), spin-coating speeds, annealing temperatures, annealing times, and ink volume ratios of the ARFs in Fig. 3.

\begin{tabular}{|c|c|c|c|c|c|c|}
\hline Refractive index & $\begin{array}{c}\text { Volume } \\
\text { ratio of LG }\end{array}$ & $\begin{array}{c}\text { Volume } \\
\text { ratio of IPA }\end{array}$ & $\begin{array}{c}\text { Volume } \\
\text { ratio of UW }\end{array}$ & Spin-coating speed [rpm] & Annealing temperature $\left[{ }^{\circ} \mathrm{C}\right]$ & Annealing time $[\mathrm{h}]$ \\
\hline 1.35 & 1 & 5 & 0 & 8000 & 300 & 1 \\
\hline 1.35 & 1 & 4.9 & 0.1 & 8000 & 300 & 1 \\
\hline 1.33 & 1 & 4.85 & 0.15 & 8000 & 300 & 1 \\
\hline 1.34 & 1 & 4.75 & 0.25 & 8000 & 300 & 1 \\
\hline 1.51 (Eagle-XG) & & & & no ARF & & \\
\hline
\end{tabular}

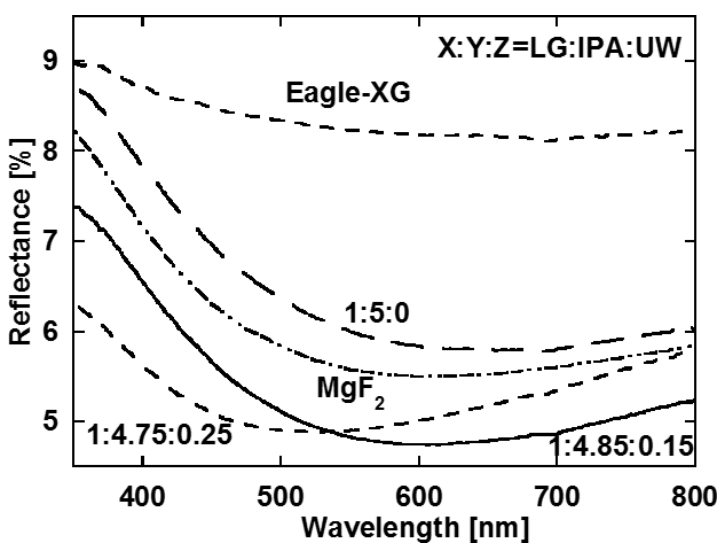

Fig. 4 Reflectance spectra of bare Eagle-XG glass substrate, $\mathrm{MgF}_{2}$, and ARFs with different dilution ratios.

The ARF prepared using the diluted ink has a higher antireflection effect than the $\mathrm{MgF}_{2}$ film. The annealing temperature was under $300^{\circ} \mathrm{C}$ for all the ARFs whose properties are shown in Figs. 3 and 4.

The relation between the antireflection effect of the ARFs and the void ratio in the film has been discussed above. ARFs were prepared under various conditions such as by using diluted ink for XRD measurement (Smart Lab System, Rigaku Corporation) to confirm the above relation. The results of the XRD measurement in Fig. 5 show that the ARFs with a lower refractive index have a larger pore size and a wide distribution of the pore size. The ink volume ratios, spin-coating speeds, annealing temperatures, and annealing times of the ARFs in Fig. 5 are shown in Table 2. The ARF fabricated using organopolysiloxane diluted with a small amount of water and annealed at about $300^{\circ} \mathrm{C}$ exhibited the best antireflection effect for solar cells.

However, the contact of the electrodes on a solar cell already installed as a module would be deteriorated by the formation of an ARFs by annealing at $300^{\circ} \mathrm{C}$ owing to the melting of the ethylene-vinyl acetate (EVA) used in the solar cell, which would adversely affect the characteristics. On the other hand, the modularization using EVA is carried out at approximately $200^{\circ} \mathrm{C}$. In this research, it was found that EVA deteriorates upon heat treatment at about $300^{\circ} \mathrm{C}$. Therefore, the formation of an ARF at room temperature (about $25^{\circ} \mathrm{C}$ ) without using an electric furnace was attempted. It was possible to obtain an ARF with an appropriate thickness by using a dilution ratio of $L G:$ IPA $=1: 4$, coating at $4000 \mathrm{rpm}$, and solidifying the film at room temperature for 7 days. However, the reflectance spectrum was not lowered as expected. The reflectance of an ARF formed

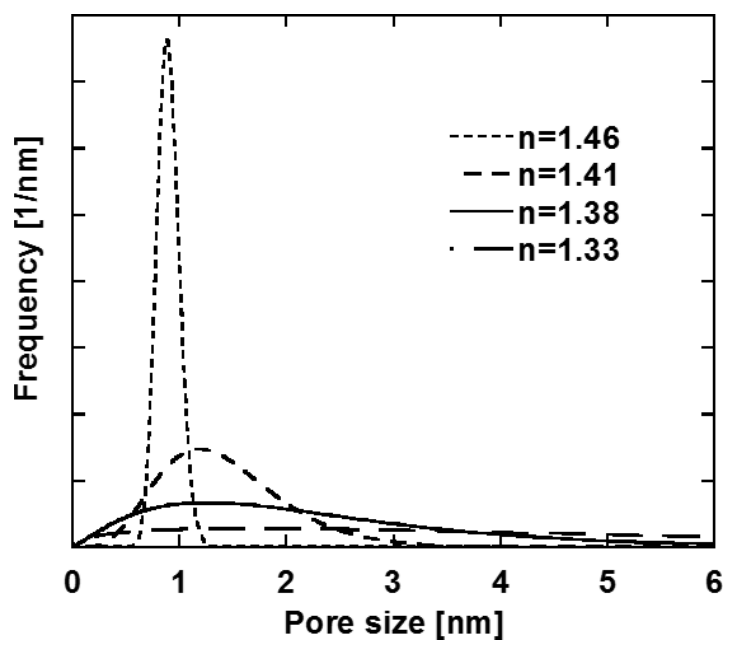

Fig. 5 Distributions of pores size in the ARFs obtained from XRD measurement.

at room temperature can be lowered by modifying the surface of the ARF. The surface of the ARF was modified by irradiation with excimer VUV light using an excimer lamp. This treatment reduced the reflectance of the film from $8.1 \%$ to $7.7 \%$ at $600 \mathrm{~nm}$ and the refractive index from 1.44 to 1.42 , which is lower than that of normal glass.

It is considered that nanobubbles were generated as the temperature increased owing to the evaporation of the organic solvent of the ink. These nanobubbles were trapped in the film before reaching the atmosphere during the solidification of the ink. Since the reaction rate of the organopolysiloxane varies with the temperature and the amount of UW, it is considered that the volume of the pores inside the ARF is related to the fabrication conditions of the ARF such as the annealing temperature and the dilution ratio of UW. Moreover, the lower distribution of the pores from the surface of the ARF to the depth direction towards the substrate, causing the refractive index to change gradually from the surface of the ARF towards the substrate according to the wide extent of the pore size distribution. This appears to enhance the antireflection effect.

Although the reflectance of the ARF after the surface modification was higher than that of the annealed ARFs using an electric furnace, it was confirmed that the reflectance was reduced after the irradiation of the excimer lamp. The reflectance spectra before and after surface modification by irradiation of the excimer lamp for $30 \mathrm{~min}$ are shown in Fig. 6 The VUV light irradiation created ozone, which etched the surface of the porous $\mathrm{SiO}_{\mathrm{x}}$. This means that the 
Table 2 Ink volume ratios, spin-coating speeds, annealing temperatures, and annealing times of the ARFs in Fig. 5.

\begin{tabular}{cccccc}
\hline Refractive index & $\begin{array}{c}\text { Volume } \\
\text { ratio of LG }\end{array}$ & $\begin{array}{c}\text { Volume } \\
\text { ratio of IPA }\end{array}$ & $\begin{array}{c}\text { Volume } \\
\text { ratio of UW }\end{array}$ & $\begin{array}{c}\text { Spin-coating speed [rpm] } \\
\left.\text { Annealing temperature [ }{ }^{\circ} \mathrm{C}\right]\end{array}$ Annealing time [h] \\
\hline 1.46 & 1 & 5 & 0 & 1000 & 25 (Room temperature) \\
\hline 1.41 & 1 & 4 & 0 & 8000 & 300 \\
\hline 1.38 & 1 & 4 & 0 & 8000 & 1600 \\
\hline 1.33 & 1 & 4.85 & 0.15 & 8000 & 300 \\
\hline
\end{tabular}

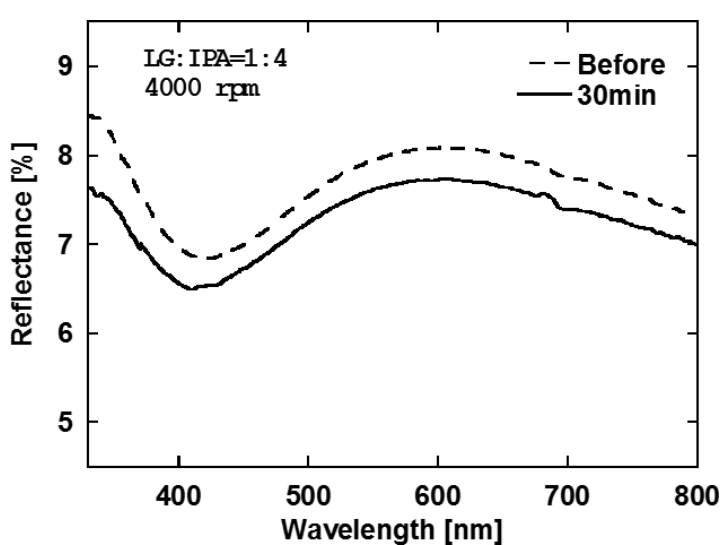

Fig. 6 Reflectance spectra of ARFs before and after the Surface Modification for $30 \mathrm{~min}$.

nanosize voids in the $\mathrm{SiO}_{\mathrm{x}}$ thin layer were etched by ozone, forming a nanoscale textures structure on the top surface. In this case, the textured structure of $\mathrm{SiO}_{\mathrm{x}}$ acts as an intermediate layer with a graded refractive index between the air and the porous $\mathrm{SiO}_{\mathrm{x}}{ }^{13)}$. Thus, the surface of the ARF was modified by the irradiation of the excimer lamp and the reflectance was reduced.

Since all of the ARFs at this stage of research were formed at room temperature, they can be applied as the cover glass of modularized solar cells. However, the further reduction of the reflectance must be achieved because of the higher reflectance of these ARFs than that of the film formed using electric furnace.

\section{Conclusions}

An ARF fabricated with LG ink based on organopolysiloxane with an ink volume ratio of LG : IPA : UW $=1$ :
4.85 : 0.15 , a spin-coating speed of $8000 \mathrm{rpm}$, and an annealing temperature of $300^{\circ} \mathrm{C}$ has a higher antireflection effect than the commonly used $\mathrm{MgF}_{2}$ film. Furthermore, the ARF can also be formed at room temperature without using an electric furnace where the antireflection effect is achieved by surface modification using an the excimer lamp.

\section{Acknowledgement}

The author would like to thank NARUSE SEIJO Ltd. for the provision of the LG.

\section{REFERENCES}

1) A.K. Barua, A. Sarker, A.K. Bandyopadhyay, D. Das and S. Ray: Proc. 28th IEEE PV Spec. Conf., (Anchorage, Alaska, USA, September 17-22, 2000), (2000) pp. 829-832.

2) W.S. Choi, K. Kim, J. Yi and B. Hong: Mater. Lett. 62 (2008) 577-580.

3) W.S. Choi and B. Hong: J. Korean Phys. Soc. 45 (2004) S864-S867.

4) C.J. Brinker and M.S. Harrington: Sol. Energy Mater. 5 (1981) 159-172.

5) H.H. Yang and G.C. Park: Trans. Electr. Electron. Mater. 11 (2010) 33-36.

6) S. Korkmaz, S. Elmas, N. Ekem, S. Pat and M.Z. Balbag: Opt. Commun. 285 (2012) 2373-2376.

7) P. Nostell, A. Roos and B. Karlsson: Solar Energy Mater. Solar Cells 54 (1998) 223-233.

8) L. Wicikowski, B. Kusz, L. Murawski, K. Szaniawska and B. Susła: Vacuum 54 (1999) 221-225.

9) T.H. Elmer (Corning), H. Waters (Painted Post), US Patent 4019 884, 26 April 1977.

10) Ö. Kesmez, H.E. Çamurlu, E. Burunkaya and E. Arpaç: Ceram. Int. 36 (2010) 391-394.

11) G. Wu, J. Wang, J. Shen, T. Yang, Q. Zhang, B. Zhou, Z. Denga, B. Fan, D. Zhoub and F. Zhang: Mater. Res. Bull. 36 (2001) 2127-2139.

12) A. Cannavale, F. Fiorito, M. Manca, G. Tortorici, R. Cingolani and G. Gigli: Build. Environ. 45 (2010) 1233-1243.

13) D.H. Raguin and G.M. Morris: Appl. Opt. 32 (1993) 2582-2598. 